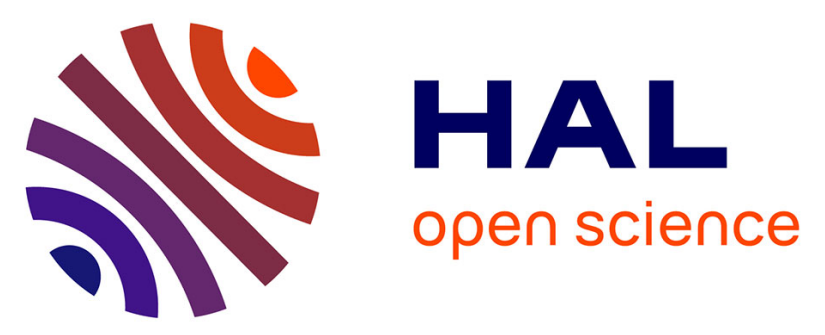

\title{
Synthesis and characterization of tin dioxide thick film modified by APTES in vapor and liquid phases
}

Mohamad Hijazi, Valérie Stambouli, Mathilde Rieu, Vincent Barnier, Guy

Tournier, Thomas Demes, Jean-Paul Viricelle, Christophe Pijolat

\section{- To cite this version:}

Mohamad Hijazi, Valérie Stambouli, Mathilde Rieu, Vincent Barnier, Guy Tournier, et al.. Synthesis and characterization of tin dioxide thick film modified by APTES in vapor and liquid phases. Journal of Materials Science, 2018, Electronic materials, 53 (1), pp.727-738. 10.1007/s10853-017-1541-4 . hal-01586224

\section{HAL Id: hal-01586224 \\ https://hal.science/hal-01586224}

Submitted on 26 Oct 2017

HAL is a multi-disciplinary open access archive for the deposit and dissemination of scientific research documents, whether they are published or not. The documents may come from teaching and research institutions in France or abroad, or from public or private research centers.
L'archive ouverte pluridisciplinaire HAL, est destinée au dépôt et à la diffusion de documents scientifiques de niveau recherche, publiés ou non, émanant des établissements d'enseignement et de recherche français ou étrangers, des laboratoires publics ou privés. 


\title{
Synthesis and characterization of tin dioxide thick film modified by APTES in
}

\section{vapor and liquid phases}

Mohamad HIJAZI ${ }^{1}$, Valérie STAMBOULI ${ }^{2}$, Mathilde RIEU ${ }^{{ }^{1 *}}$, Vincent BARNIER ${ }^{3}$, Guy TOURNIER ${ }^{1}$, Thomas DEMES ${ }^{2}$, Jean-Paul VIRICELLE ${ }^{1}$, Christophe PIJOLAT ${ }^{1}$

${ }^{1}$ École Nationale Supérieure des Mines, SPIN-EMSE, CNRS:UMR5307, LGF, F-42023 SaintÉtienne, France

${ }^{2}$ LMGP, Université Grenoble-Alpes, Grenoble INP-MINATEC, 3 parvis Louis Néel, CS 50257, 38016 Grenoble Cedex 1, France

${ }^{3}$ École Nationale Supérieure des Mines, SMS-EMSE, CNRS:UMR5307, LGF, F-42023 SaintÉtienne, France

*Corresponding author: Mathilde Rieu, rieu@emse.fr, Tel.: +33477420282

\begin{abstract}
Surface functionalization has numerous applications worldwide. Silicon oxide has been a research material of choice. However, tin dioxide $\left(\mathrm{SnO}_{2}\right)$ films are employed in many applications especially in gas sensors, and little studied in regards of functionalization. Thus, they were chosen to be functionalized via 3-aminopropyltriethoxysilane (APTES). Different synthesis parameters were tested such as APTES grafting by vapor or liquid phases deposition. In liquid, many parameters were investigated: water presence, reaction times and APTES concentration. The presence and reactivity of grafted amine terminated film on $\mathrm{SnO}_{2}$ were carried out by Alexa Fluor ${ }^{\circledR}$ molecules. In addition, APTES grafting was characterized using Attenuated Total Reflectance-Fourier Transform Infrared spectroscopy (ATR-FTIR) and X-ray photoelectron spectrometry (XPS) techniques. These characterizations showed how synthesis parameters affect the amount and thickness of APTES films. Optimal liquid silanization parameters were determined in order to obtain a saturated $\mathrm{SnO}_{2}$ surface with APTES molecules. Importantly, the addition of $5 \mathrm{vol} \% \mathrm{H}_{2} \mathrm{O}$ to the APTES solution provided denser surface coverage, by hydrolyzing the ethoxy groups to silanol. An almost 50\% improvement over anhydrous liquid and vapor methods was obtained.
\end{abstract}

Keywords: $\mathrm{SnO}_{2}$; Functionalization; APTES; XPS; ATR-FTIR 


\section{Introduction}

Surface functionalization is being used in wide range of applications, like surface and selfassembling monolayers (SAMs) in bio-sensors [1,2], gas sensors [3-5], corrosion resistance of metal [6] and electronics [7]. Generally, surfaces are organically modified to enhance detection performance, surface rigidity, selectivity and sensitivity of sensors, etc. [6, 8-10]. Silanization or covering of a metal oxide surface self-assembly with organofunctional alkoxysilane molecules, using organosilanes $\left(\mathrm{RSiX}_{3}\right.$ where $\mathrm{R}$ is an alkyl or any other functional group and $\mathrm{X}$ is a leaving group) is the most commonly used method to prepare active organic monolayers on oxide films [11]. 3-aminopropyltriethoxysilane (APTES) is one of the most commonly used organosilane products to prepare an active amine terminated film on metal oxides [8]. The main advantage of an aminosilane monolayer on the surface of metal oxide is the rapid formation of covalent bonds between the oxide surface and the anchoring groups, thus stabilizing the monolayer and facilitating further modifications [12]. Furthermore, APTES has bulky alkoxy groups that improve the stability of the resulting monolayer as shown by Feng Zhang et al. [13].

The APTES films can be generally deposited on silicon and tin dioxide substrates. These films are used to attach a variety of materials such as DNA, proteins and polymers [2, 6, 14]. Moreover, the APTES molecule can also be used as intermediate step for advanced modification/functionalization in gas sensors $[4,5,15]$. To the best of our knowledge, the properties of these films such as thickness, orientation and density of the monolayer have essentially been investigated on silicon oxide [16-19]. However, only a few studies on the preparation of the APTES layer deposited on tin dioxide surface have been explored [1], even though these reactive films are also being used as gas and bio-sensors. Indeed, tin dioxide $\left(\mathrm{SnO}_{2}\right)$ is being used in many fields like gas sensors, biosensors, and electronics [2, 20, 21]. $\mathrm{SnO}_{2}$ is often chosen for gas sensors due to its unique physical and chemical properties such as a large energy gap $(3.6 \mathrm{eV})$, dielectric constant, better accuracy or repeatability at the present stage of development, environmental-friendliness and easy to synthesize. As in $\mathrm{SiO}_{2}$, functionalizing $\mathrm{SnO}_{2}$ by organic molecules is of special interest to improve sensitivity, selectivity, and electrical properties in gas sensor applications and others.

In this work, we propose to study the modification of $\mathrm{SnO}_{2}$ thick films by APTES since it is not well described in the literature. The aim was to prepare active and stable amine terminated 
organic film on $\mathrm{SnO}_{2}$ thick film prepared by a screen printing technique. Functionalization of $\mathrm{SnO}_{2}$ film by APTES in vapor and liquid phase was investigated. Furthermore, varying silanization parameters in the liquid route like the influence of condensation reaction time, APTES concentration, and the effects of water during the reaction were examined. Finally, concentration and thermal stability of APTES on $\mathrm{SnO}_{2}$ were also evaluated.

\section{Experimental}

\subsection{Preparation of $\mathrm{SnO}_{2}$ film and silanization procedures}

\subsubsection{Preparation of $\mathrm{SnO}_{2}$ film}

Thick $\mathrm{SnO}_{2}$ films were deposited on alumina substrate by screen-printing technology. A semiautomatic Aurel C890 machine was used. Procedure to prepare the $\mathrm{SnO}_{2}$ ink and film fabrication parameters was described elsewhere [22]. First, the $\mathrm{SnO}_{2}$ powder (Prolabo Company) was mixed with a solvent and an organic binder. Second, a 40 microns oxide film (approximately) was

deposited on an alpha-alumina substrate $\left(8 \times 8 \times 0.4 \mathrm{~mm}^{3}\right)$. Finally, the $\mathrm{SnO}_{2}$ material was annealed for $10 \mathrm{~h}$ at $700{ }^{\circ} \mathrm{C}$ in air. The $\mathrm{SnO}_{2}$ particles and agglomerates sizes were found to be between 10 $\mathrm{nm}$ and $500 \mathrm{~nm}$.

\subsubsection{Vapor phase silanization}

The silanization of $\mathrm{SnO}_{2}$ film by 3-aminopropyltriethoxysilane (Acros-Organics) in vapor phase has been described elsewhere [16]. First, the $\mathrm{SnO}_{2}$ films were immersed for $5 \mathrm{~min}$ in acetone, ethanol and distilled water (DW) successively, and then dried with argon to remove contaminants. Second, films were treated by air/oxygen plasma (air/ $\mathrm{O}_{2}$ pressure $=0.4$ torr) for 4 min to create hydroxyl groups on the sample surface. Third, the $\mathrm{SnO}_{2}$ sample and APTES (liquid) were placed side by side in closed Teflon holder. Then, the liquid was baked out at $80{ }^{\circ} \mathrm{C}$ for $1 \mathrm{~h}$. The installation of $\mathrm{SnO}_{2}$ samples and $150 \mu \mathrm{L}$ of APTES was conducted in a dry atmosphere to avoid the humidity in cell. After $1 \mathrm{~h}$ silanization, the samples were rinsed with absolute ethanol. Finally, the films were annealed at $110{ }^{\circ} \mathrm{C}$ for $1 \mathrm{~h}$ to eliminate water trapped in the films as well as the physisorbed APTES molecules. A scheme of APTES vapor phase deposition on $\mathrm{SnO}_{2}$ is presented in the Fig. 1. 


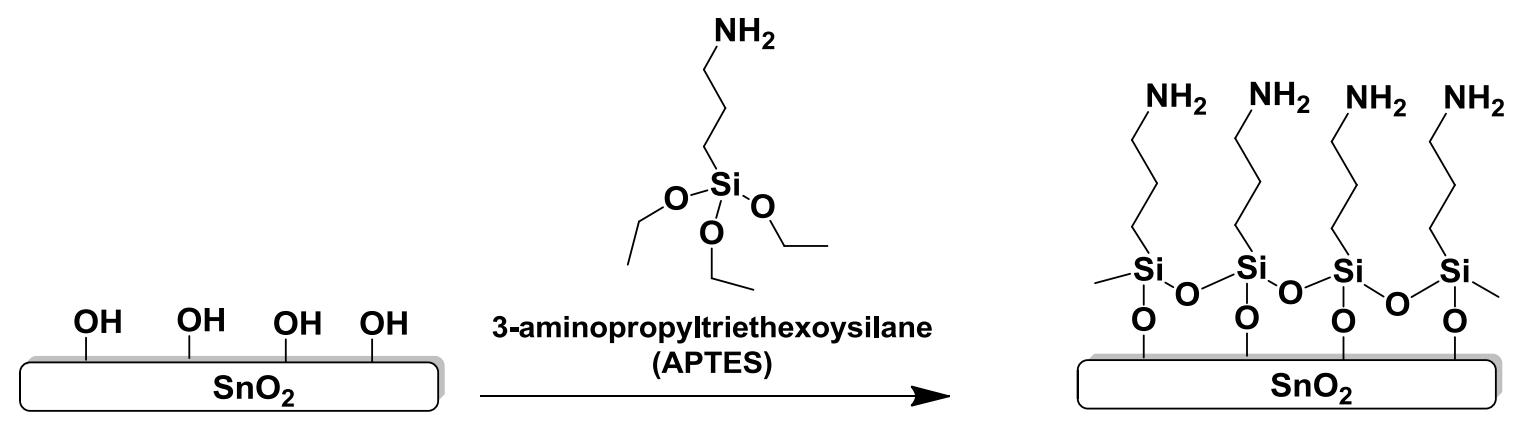

Fig. 1. Schematic representation of the silanization process.

\subsubsection{Liquid phase silanization}

The liquid phase grafting of APTES considered the influence of three main parameters: anhydrous and hydrous APTES solution, APTES concentration, and reaction time. All the solutions were prepared in absolute ethanol (anhydrous ethanol). The silanization was performed by immersing the $\mathrm{SnO}_{2}$ films in the APTES solution, with or without water, with three different APTES concentrations $(1,50$ or $500 \mathrm{mM})$ at room temperature and for various durations: $5 \mathrm{~min}$, $30 \mathrm{~min}, 4 \mathrm{~h}$, and $5 \mathrm{~h}$. To investigate whether water would hydrolyze the ethoxy groups, the 50 mM APTES solution was diluted with 5 vol\% $\mathrm{H}_{2} \mathrm{O}$ (hydrous APTES solution; i.e. solvent: $95 \%$ by volume of absolute ethanol and $5 \%$ of $\mathrm{H}_{2} \mathrm{O}$ ) for $5 \mathrm{~min}, 30 \mathrm{~min}, 4 \mathrm{~h}$ and $5 \mathrm{~h}$ immersion times. For varying hydrous APTES concentrations (1, 50 or $500 \mathrm{mM}), \mathrm{SnO}_{2}$ was immersed for $5 \mathrm{~h}$. After silanization, the films were rinsed with absolute ethanol, dried with $\mathrm{N}_{2}$ and annealed at 110 ${ }^{\circ} \mathrm{C}$ for $1 \mathrm{~h}$. The reaction carried out in absolute ethanol, $50 \mathrm{mM}$ APTES solution for $5 \mathrm{~h}$ will be called anhydrous liquid silanization.

\subsection{Characterization techniques}

$\mathrm{SnO}_{2}$-APTES film can be used as intermediate step for further surface modifications. The reactivity of APTES film with respect to coupling reactions was determined by using Alexa Fluor ${ }^{\circledR} 488$ carboxylic acid, succinimidyl ester molecule $\left(\lambda_{\text {exitation }}=488 \mathrm{~nm}\right)$. Alexa Fluor product was purchased from Life Technologies. This product reacts specifically with the primary amines that lead eventually to immobilization of florescent molecules on $\mathrm{SnO}_{2}$ film. To study the feasibility of employing fluorescent molecules on APTES films, two $\mathrm{SnO}_{2}$ samples, one with APTES ( $\mathrm{SnO}_{2}$-APTES) and the other without APTES, were immersed for one hour in a mixture 
of $4 \mu \mathrm{L}$ of Alexa Fluor and $3 \mathrm{~mL}$ of solution of sodium carbonate and sodium bicarbonate, $\mathrm{pH} 9$, at room temperature. Afterwards, the samples were rinsed with absolute ethanol. Alexa Fluor molecules were detected by epifluorescence measurements using an BX41M optical microscope (Olympus, Tokyo, Japan), fitted with a $100 \mathrm{~W}$ mercury lamp, a cyanide Cy3 dichroic cube filter (excitation $550 \mathrm{~nm}$, emission $580 \mathrm{~nm}$ ) and a cooled Spot RT monochrome camera (Diagnostic, Sterling Heights, MI, USA). The intensity of film fluorescence was measured by Tecan Infinite M1000 in order to determine qualitatively the APTES on the surface of $\mathrm{SnO}_{2}$ film. The fluorescence intensity measurements were carried out at $494 \mathrm{~nm}$ as excitation wavelength and $517 \mathrm{~nm}$ emission wavelength with an integration time of $20 \mu$ s and a settle time of $10 \mathrm{~ms}$.

The influence of silanization parameters (vapor or liquid synthesis, and in liquid process: water content, APTES concentration, reaction time) were evaluated via Attenuated Total ReflectanceFourier Transform Infra-Red spectroscopy (ATR-FTIR). Samples were placed face-down on the diamond crystal, and a force was manually applied by pressure tip. FTIR spectra were recorded in wavelengths ranging from 400 to $4000 \mathrm{~cm}^{-1}$ with a resolution of $2 \mathrm{~cm}^{-1}$. The entire ATR-FTIR spectra were collected using a Golden Gate Diamond ATR accessory (Bruker Vertex 70).

In order to check the presence, concentration, and the thermal stability of APTES films on $\mathrm{SnO}_{2}$, chemical surface analysis were carried out using X-ray Photoelectron Spectroscopy XPS. The analysis were performed with a Thermo VG Thetaprobe instrument with a focused monochromatic $\mathrm{Al} \mathrm{Ka}$ source ( $\mathrm{h} v=1486.6 \mathrm{eV}, 400 \mu \mathrm{m}$ spot size). Photoelectrons were analyzed using a concentric hemispherical analyzer operating in the constant $\Delta \mathrm{E}$ mode. The energy scale was calibrated with sputter-cleaned pure reference samples of $\mathrm{Au}, \mathrm{Ag}$ and $\mathrm{Cu}$ in order that the $\mathrm{Au}$ 4f7/2, Ag 3d5/2 and $\mathrm{Cu} 2 \mathrm{p} 3 / 2$ were positioned at a binding energies of respectively 84, 386.2 and $932.7 \mathrm{eV}$. Spectra were recorded in the binding energy range of 0-1200 eV with step size of $1 \mathrm{eV}$ and pass energy of $300 \mathrm{eV}$ for survey scans, step size of $0.1 \mathrm{eV}$ and pass energy of $50 \mathrm{eV}$ for narrow C 1s, O1s, N 1s, Si 2p, Sn 4d and Sn 3d scans. The two pass energies give energy resolution (width of the $\mathrm{Ag} 3 \mathrm{~d} 5 / 2$ peak) measured on sputter clean silver samples of respectively $1 \mathrm{eV}$ and $0.5 \mathrm{eV}$. During XPS experiments, charge compensation was achieved by irradiation of the sample with a system combining a diffuse beam of low energy electrons and low energy ions. Optimum charge compensation was performed in order to have the narrower-shape of the tail at 
the low binding energy of Sn 3d peak. Analysis of the different components of C 1s, O 1s, N 1s and Si 2p photoelectron peaks were carried out using synthetic line shapes consisting of a convolution product of a Gaussian function with $30 \%$ of a lorentzian function. To study APTES thermal stability, $\mathrm{SnO}_{2}$-APTES films were in-situ annealing at $200{ }^{\circ} \mathrm{C}, 300{ }^{\circ} \mathrm{C}, 400{ }^{\circ} \mathrm{C}$ and 500 ${ }^{\circ} \mathrm{C}$, for $4 \mathrm{~h}$ in a preparation chamber connected to the spectrometer at a pressure of $5.10^{-9} \mathrm{mbar}$.

\section{Results and Discussions}

\subsection{Influence of silanization process and synthesis parameters.}

Figure 2 shows the epifluorescence microscope images of $\mathrm{SnO}_{2}$ (Fig. 2a) and $\mathrm{SnO}_{2}$-APTES after silanization in vapor (Fig. 2b) and liquid phase (synthesis parameters: $50 \mathrm{mM}$ of hydrous APTES solution, immersed for 5 h, Fig. 2c) modified by Alexa Fluor. For $\mathrm{SnO}_{2}$ (Fig. 2a), no fluorescence is observed. On the contrary, the obtained fluorescence of $\mathrm{SnO}_{2}$-APTES films (Fig. 2b and 2c) means that the Alexa Fluor molecules were attached to the surface by the grafted amine terminal film of APTES. The fluorescence intensity of APTES modified $\mathrm{SnO}_{2}$ in vapor phase was 3185 in arbitrary units while it was 4541 by liquid silanization. The fluorescence intensities show that more reactive amine groups are present on the surface for the $\mathrm{SnO}_{2}$-APTES carried out in liquid phase.
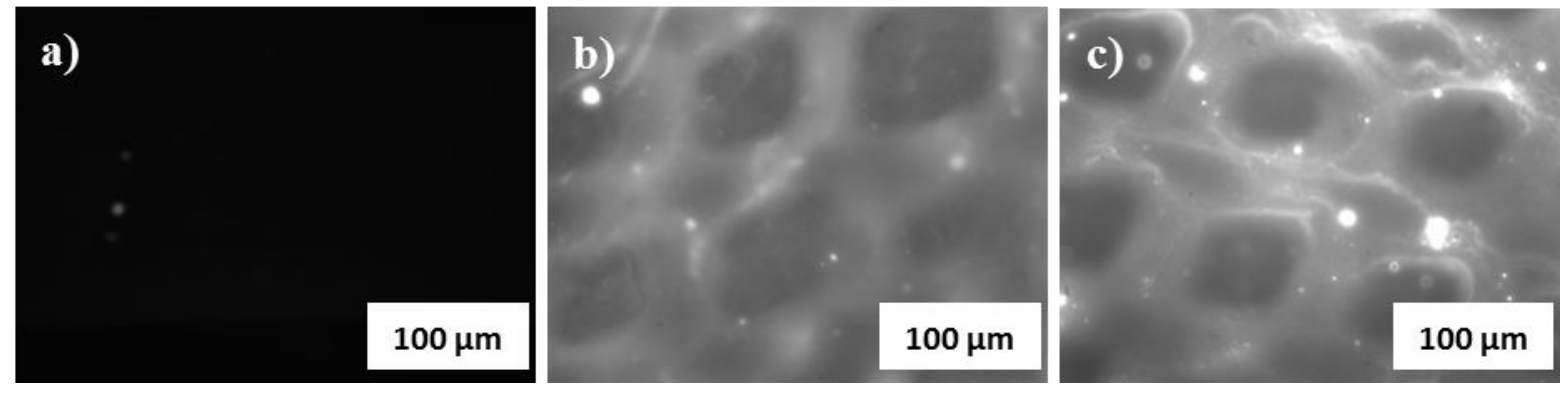

Fig. 2. Epifluorescence images after immersion in Alexa Fluor solution: a) $\mathrm{SnO}_{2}$, b) $\mathrm{SnO}_{2}$ APTES-vapor phase and c) $\mathrm{SnO}_{2}$-APTES-liquid phase ( $5 \mathrm{vol} \% \mathrm{H}_{2} \mathrm{O}, 50 \mathrm{mM}$ of APTES, $5 \mathrm{~h}$ ).

In order to compare the synthesis parameters, Attenuated Total Reflectance-Fourier Transform Infra-Red spectroscopy (ATR-FTIR) was used. The most important signals corresponding to APTES were found between 800 and $1800 \mathrm{~cm}^{-1}$ as shown in Fig. 3. The peak at $938 \mathrm{~cm}^{-1}$ is 
attributed to Sn-O-Si stretch [4]. The strong mode at $1029 \mathrm{~cm}^{-1}$ is attributed to siloxane group (Si$\mathrm{O}-\mathrm{Si}$ ) from polymerized APTES, this mode being proportional to the thickness of the APTES layer [23]. The peak at $1070 \mathrm{~cm}^{-1}$ arises from the un-hydrolyzed ethoxy groups of APTES ($\mathrm{OCH}_{2} \mathrm{CH}_{3}$ ) [24]. The strong absorption peak at $1125 \mathrm{~cm}^{-1}$ is attributed to Si-O bond of either polymerized or physisorbed APTES [17]. The vibrational mode around $1390 \mathrm{~cm}^{-1}$ is assigned to Si-C bond (-Si- $\left.\mathrm{CH}_{2-}\right)$ [17]. $\mathrm{NH}_{2}$ vibrational signal is found at $1570 \mathrm{~cm}^{-1}$ and confirms the presence of amine end functional group of APTES after silanization. The two peaks present at 1496 and $1643 \mathrm{~cm}^{-1}$ correspond respectively to the symmetric and asymmetric $-\mathrm{NH}_{3}{ }^{+}$group indicating the protonation of amine group in air $[25,26]$.

Different parameters were explored for APTES grafting: vapor and liquid silanization with or without $\mathrm{H}_{2} \mathrm{O}$ (Fig. 3a), APTES concentrations (Fig. 3b) and reaction times (Fig. 3c). As shown in Fig. 3 a), APTES liquid synthesis with 5 vol\% $\mathrm{H}_{2} \mathrm{O}$ (red curve) shows more intense vibrational modes which imply that more APTES molecules were grafted on the surface in this synthesis. Furthermore, the observed peak at $1070 \mathrm{~cm}^{-1}$ in the case of vapor silanization (green curve) and liquid synthesis without $\mathrm{H}_{2} \mathrm{O}$ (blue curve) is linked to un-hydrolyzed ethoxy groups of APTES as mentioned earlier. This peak has disappeared for the $\mathrm{SnO}_{2}$-APTES film done with $\mathrm{H}_{2} \mathrm{O}$. The water molecules initiate the silanization process by hydrolysis of ethoxy groups to create corresponding hydroxysilane $\left(\mathrm{RSi}(\mathrm{OH})_{3}\right)$ [12]. Hydrolysis of ethoxy groups of APTES pushes forward the condensation reaction with $\mathrm{SnO}_{2}$ film and with APTES to each other [26, 27]. From these results, one can notice that the presence of water in the synthesis solution increases the APTES grafting on $\mathrm{SnO}_{2}$ with also more APTES molecules bonding. 

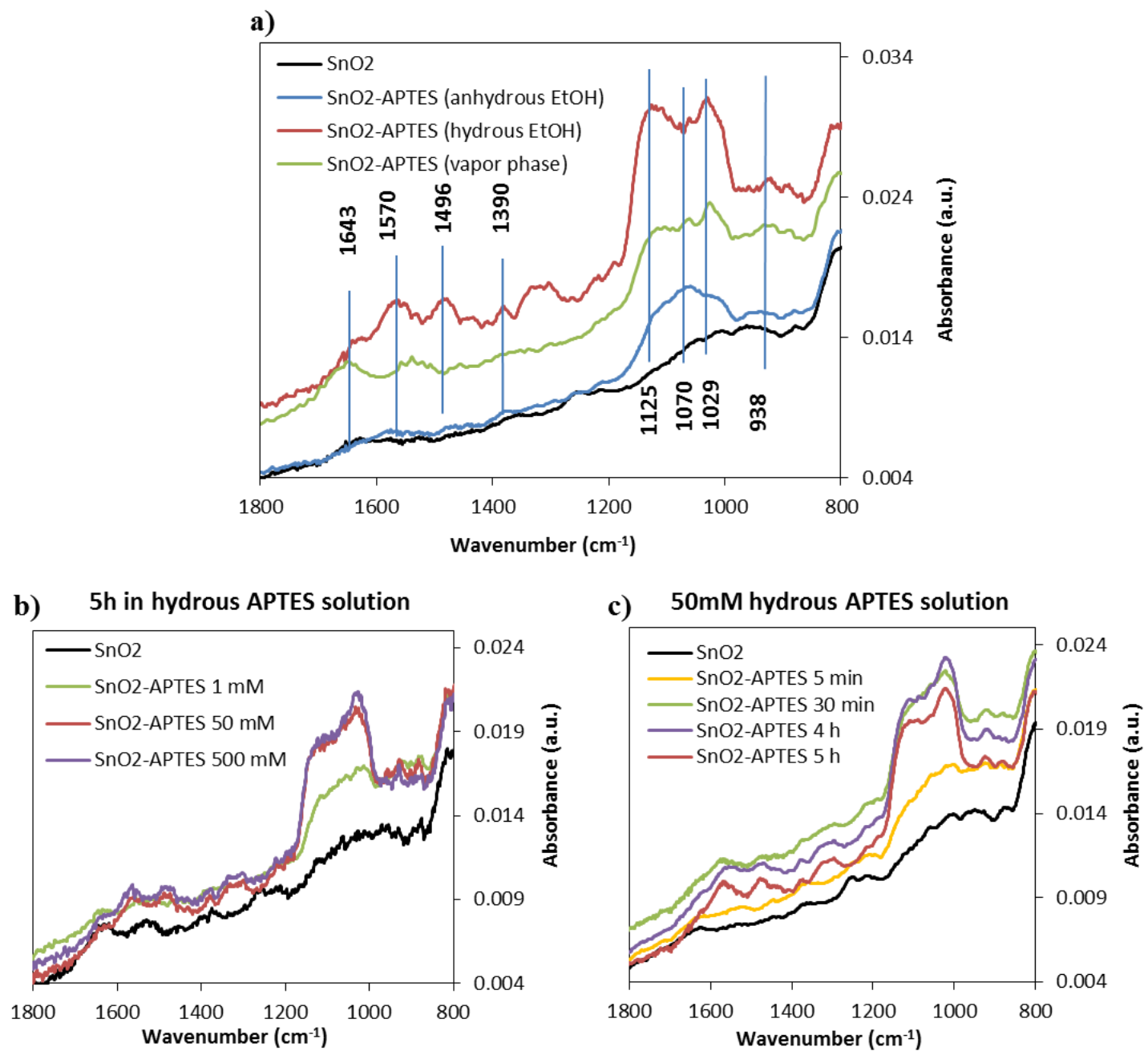

Fig. 3. ATR-FTIR spectra of $\mathrm{SnO}_{2}$ and $\mathrm{SnO}_{2}$-APTES with different silanization parameters: a) vapor phase and liquid phase in ethanol with and without $\mathrm{H}_{2} \mathrm{O}, 50 \mathrm{mM}$ APTES, $5 \mathrm{~h}$, b) hydrous liquid phase in ethanol (5 h); APTES concentrations of 1,50 and $500 \mathrm{mM}, \mathrm{c}$ ) hydrous liquid phase in ethanol (50 mM APTES); immersion times of $5 \mathrm{~min}, 30 \mathrm{~min}, 4 \mathrm{~h}$ and $5 \mathrm{~h}$.

In Fig. 3 b), 3 APTES concentrations were tested in ethanol solution with $5 \mathrm{vol} \% \mathrm{H}_{2} \mathrm{O}$ for $5 \mathrm{~h}$. Peaks intensities of Si-O bonds at 1029 and $1125 \mathrm{~cm}^{-1}$ are low with $1 \mathrm{mM}$ APTES solution (green curve) while they increase with $50 \mathrm{mM}$ (red curve) and then almost no change is noticed when the concentration is increased up to $500 \mathrm{mM}$ (purple curve). That means that a very little amount of APTES was grafted on the surface with a concentration of $1 \mathrm{mM}$ while a concentration of 50 $\mathrm{mM}$ was sufficient for appropriate APTES functionalization. 
Figure $3 \mathrm{c}$ ) shows different reaction times of $\mathrm{SnO}_{2}$ film in APTES solution (ethanol with 5 vol\% $\mathrm{H}_{2} \mathrm{O}, 50 \mathrm{mM}$ of APTES). The peak of Si-O-Si $\left(1029 \mathrm{~cm}^{-1}\right)$ rises with the increase of reaction time. As this peak is proportional to the amount of APTES attached on the surface [23], one can note that the increase of reaction time from $5 \mathrm{~min}$ to $4 \mathrm{~h}$ attaches a larger amount to the surface. No surge in the amount of grafted APTES on the surface was observed after $4 \mathrm{~h}$, since the signal intensity is the same between films immersed 4 and $5 \mathrm{~h}$. Evidently, this steady state means that 4 $\mathrm{h}$ is sufficient to saturate the $\mathrm{SnO}_{2}$ film with APTES.

\subsection{Surface concentration of APTES on $\mathrm{SnO}_{2}$}

\subsubsection{Film as synthetized}

The XPS survey scan spectrum of $\mathrm{SnO}_{2}$-APTES film obtained by liquid phase synthesis, presented in Fig. 4 shows the presence of $\mathrm{Sn}$ and $\mathrm{O}$ related to the $\mathrm{SnO}_{2}$ substrate and as well as $\mathrm{N}$, $\mathrm{C}$ and Si related to APTES molecules at the surface which confirms the silanization of $\mathrm{SnO}_{2}$.

Similar surveys spectrum were found for the others APTES film synthesis methods.

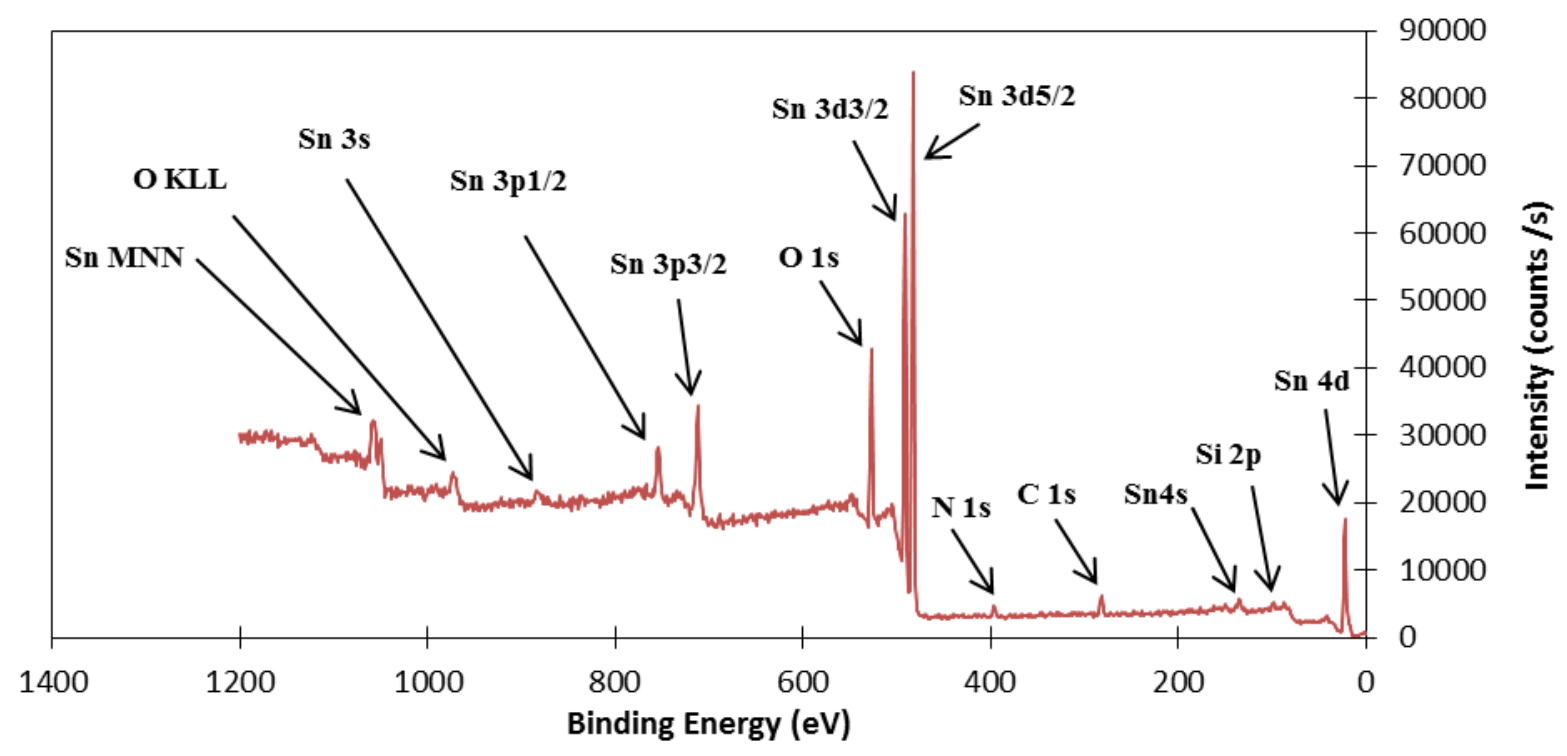

Fig. 4. XPS survey spectrum of $\mathrm{SnO}_{2}$-APTES synthesized in hydrous liquid phase.

Peak fitting of C 1s, O 1s, N 1s and Si 2p narrow scans allowed to determine different chemical bonds which were in agreement with the presence of APTES molecules as shown in Fig. 5. Three components at $284.2 \mathrm{eV}, 284.9 \mathrm{eV}$ and $289.5 \mathrm{eV}$ were found for $\mathrm{C}$ 1s peak (Fig. 5a) which were 
assigned respectively to $\mathrm{C}-\mathrm{Si}, \mathrm{C}-\mathrm{C} / \mathrm{CH}$ and $\mathrm{C}-\mathrm{N}$ chemical bonds. The nitrogen $\mathrm{N} 1 \mathrm{~s}$ core level (Fig. 5b) exhibits two contributions, one located at $399.4 \mathrm{eV}$ which is related to amine group bounded to carbon C-NH . The second located at $401.3 \mathrm{eV}$, could be attributed to C- $\mathrm{NH}_{3}{ }^{+}$[28] The shape of the $\mathrm{O}$ 1s peak (Fig. 5c) was adjusted using two components at $530.3 \mathrm{eV}$, and 531.8 $\mathrm{eV}$ according to oxygen in $\mathrm{Sn}-\mathrm{O}$, and $\mathrm{Si}-\mathrm{O}$ respectively [2]. Finally, the $\mathrm{Si} 2 \mathrm{p}$ peak located at $101.9 \mathrm{eV}$ (Fig. 5d) was assigned to Si atom bounded to oxygen and carbon in the APTES molecule. Comparing with the two others experimental procedures for silanization of $\mathrm{SnO}_{2}$, the only difference was observed on the shape at the low binding energy of the $O 1$ s peak for the hydrous liquid silanization procedure which was attributed to the presence of residual $\mathrm{H}_{2} \mathrm{O}$.
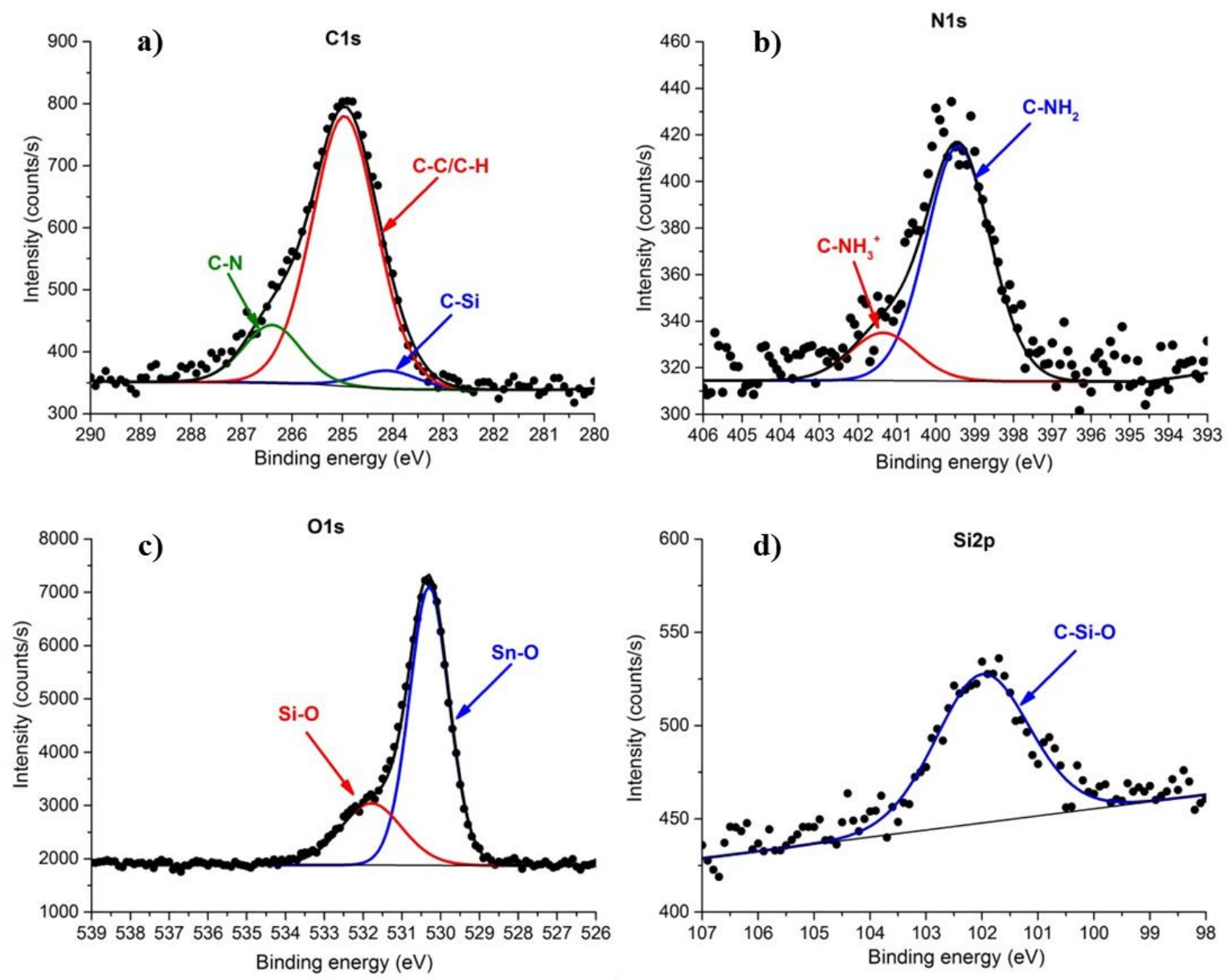

Fig. 5. XPS peak fitting of a) $\mathrm{C} 1 \mathrm{~s}$, b) $\mathrm{N} 1 \mathrm{~s}$, c) O 1s, and d) $\mathrm{Si} 2 \mathrm{p}$ of $\mathrm{SnO}_{2}$-APTES film. 


\subsubsection{Nanostructure of the APTES film on $\mathrm{SnO}_{2}$}

Nanostructure of the APTES film was determined from inelastic electron background analysis of the $\mathrm{Sn} 3 \mathrm{p}$ transition taking advantage of the weak sensitivity of this method to the roughness. "Analyze" program from QUASES software package developed by Tougaard [29] was used by means of the active substrate model where the modelled signal originates from the $\mathrm{SnO}_{2}$ substrate and is attenuated by an overlayer constituted of APTES molecules. The shape of the measured spectrum $J(E)$ strongly depends on the morphology of the overlayer. A primary excitation spectrum $F(E)$ is obtained after correction of the measured spectrum $J(E)$ by an inelastic background calculated for a given coverage and thickness of the overlayer. These set of parameters can be adjusted using two criterions. The first one is that after background subtraction $\mathrm{F}(\mathrm{E})$ must be of zero intensity in an energy region beyond $30 \mathrm{eV}$ below the primary peak energy. As a second criterion, $\mathrm{F}(\mathrm{E})$ can be compared to the one determined from the analysis of spectrum on reference sample with well-known in depth concentration profile. Reference Sn 3p spectrum was recorded on a pure $\mathrm{SnO}_{2}$ sample. After linear background subtraction and analyzer transmission function correction, the background of the model spectrum was adjusted to zero by

analyzing the reference to the depth of $1000 \AA$ that corresponds to the infinite thick homogeneous layer. The background was calculated using 'Universal cross section' formula [30] for the inelastic electron cross section and changing the "x-scale" parameter in the QUASES program from default value to 0.97 . A value of $12.36 \AA$ for the inelastic mean free path of Sn $3 p$ electrons in $\mathrm{SnO}_{2}$ was considered according to the TPP2M method [31]. The same procedure and parameters were used for analyzing $\mathrm{SnO}_{2}$ covered with APTES molecules using "active substrate" model.

Results obtained after analysis of $\mathrm{Sn} 3 \mathrm{p}$ spectrum measured on $\mathrm{SnO}_{2}$ samples with different methods of silanization are presented in the Fig. 6. From these results, two main conclusions can be drawn. Firstly, for the three methods of silanization (vapor, hydrous liquid, anhydrous liquid), the nanostructure of the grafted film consist of a monolayer of APTES molecules which does not cover entirely the surface. Secondly, the silanization procedures used can be classified as "high coverage" for the hydrous liquid method $\left(\mathrm{SnO}_{2}\right.$ surface coverage of 0.8$)$ and "low coverage" for the two other methods where a similar $\mathrm{SnO}_{2}$ surface coverage around 0.5 was found. 
Finally, it is worth noting that considering a theoretical length of the APTES molecule of $8 \AA$, the calculated overlayer thickness of $6 \AA$ indicate a $\sim 42^{\circ}$ grafting angle of the APTES molecules with respect to the normal of the $\mathrm{SnO}_{2}$ surface.

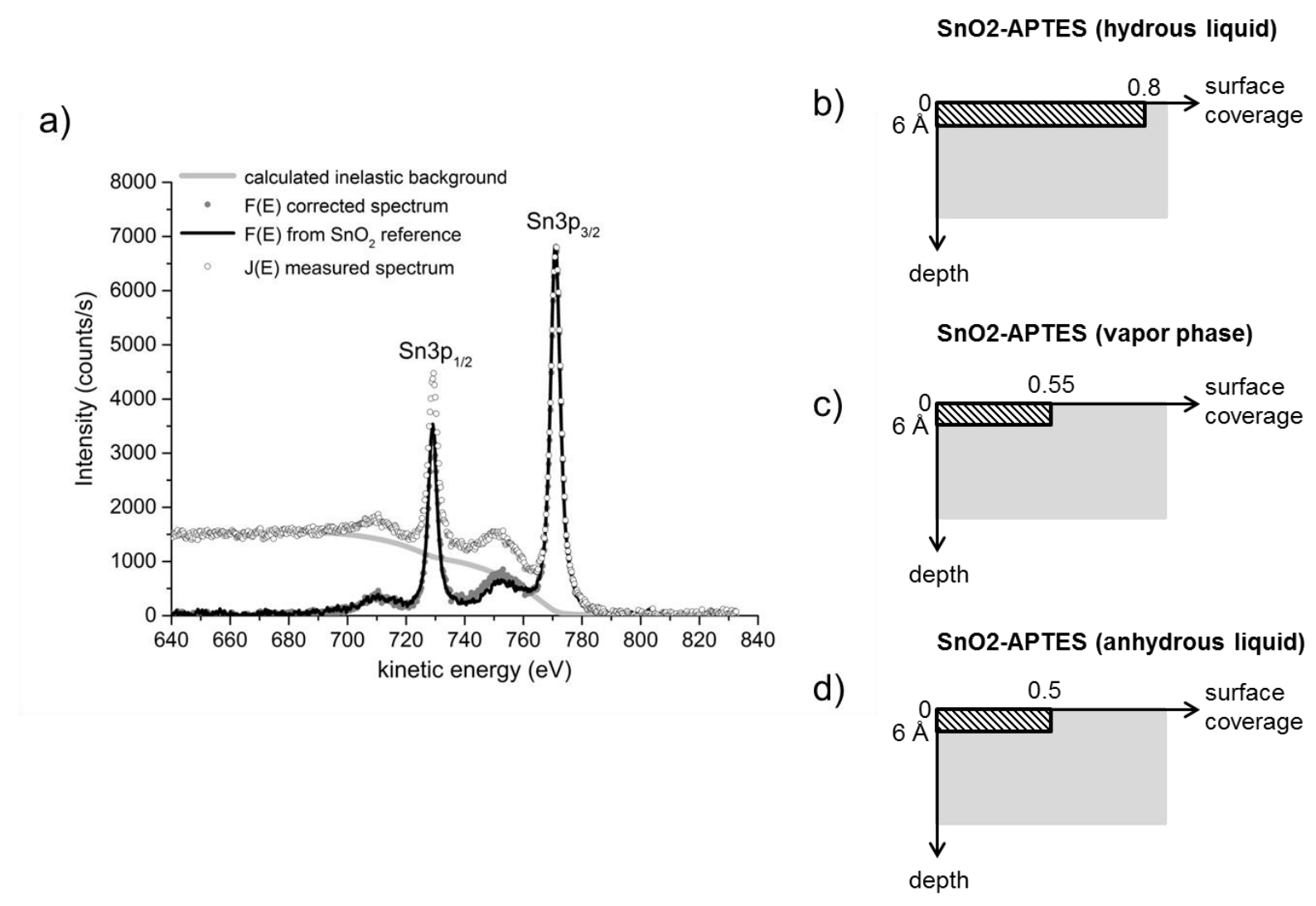

Fig. 6. a) Modelisation of the electron inelastic background of Sn 3p using QUASES software [29], b) c) and d) schematic representations of the coverage and thickness of the APTES overlayer for the three methods used for the silanization of $\mathrm{SnO}_{2}$.

\subsubsection{Determination the concentration of APTES on $\mathrm{SnO}_{2}$}

As shown before using electron inelastic background analysis, the silanization of $\mathrm{SnO}_{2}$ with vapor, hydrous liquid and anhydrous liquid methods produce a monolayer film of APTES molecules which does not cover entirely the $\mathrm{SnO}_{2}$. Owing to the difference in coverage rate according to the experimental silanization protocol, it seems interesting to determine the concentration of APTES molecules grafted on $\mathrm{SnO}_{2}$ for each method. Considering one silicon atom for each APTES molecule, these concentrations were estimated calculating the silicon 
concentration per unit area using the ratio of the intensities of Si $2 \mathrm{p}$ and $\mathrm{Sn} 4 \mathrm{~d}$ photoelectron peaks. The choice of these peaks, especially $\mathrm{Sn} 4 \mathrm{~d}$ which is much less intense than $\mathrm{Sn} 3 \mathrm{~d}$, was motivated by the fact that several assumptions can be made due to the position at high kinetic energies of these transitions as we will see below. For the purpose of this calculation, we define three thicknesses: $\mathrm{d}_{\mathrm{C}_{3} \mathrm{NH}_{8}}, \mathrm{~d}_{\mathrm{Si}}$ and $\mathrm{d}_{\mathrm{APTES}}$. These parameters are presented in the Fig. 7 and correspond to different portions of the APTES film.

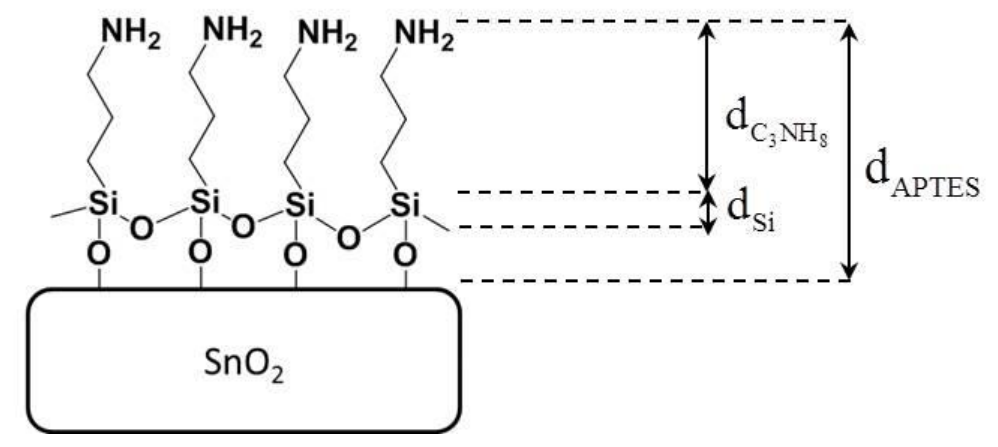

Fig. 7. Schematic illustration of the different portions of the APTES film considered for the calculation of the APTES surface concentration using the ratio of Si $2 p$ and $\mathrm{Sn} 4 \mathrm{~d}$ intensities.

Using the description in Fig. 7, the intensities of Si 2p and Sn 4d can be described as shown in equations 1 and 2 .

Eq. (1)

$$
I_{S i 2 p}=K T_{S i 2 p} \sigma_{S i 2 p} N_{S i} \lambda_{S i 2 p}^{S i} \cos \theta\left[1-\exp \left(\frac{-d_{S i}}{\lambda_{S i 2 p}^{S i} \cos \theta}\right)\right] \times k_{s i 2 p}^{C_{3} H_{8}}
$$

$$
I_{S n 4 d}=K T_{S n 4 d} \sigma_{S n 4 d} N_{S n} \lambda_{S n 4 d}^{S_{S n}} \cos \theta \times k_{S n 4 d}^{A P T E S}
$$

with

$K$ depending on instrumental factors and analysis conditions ( $\mathrm{K}$ is the same for all elements during the analysis of a given specimen),

$T_{A}$ the transmission function of the spectrometer at a kinetic energy corresponding to the photoelectron peak A, 
$\sigma_{A}$ the photoionization cross section of the core level A,

$N_{x}$ the atomic concentration per unit volume of the element $\mathrm{x}$,

$\theta$ the escape angle of photoelectrons with respect to the normal of the surface of the analyzed specimen,

$k_{A}^{M}=\exp \left(\frac{-d_{M}}{\lambda_{A}^{M} \cos \theta}\right)$ the attenuation factor of an electron of $\mathrm{A}$ in the matrix $\mathrm{M}$ and

$\lambda_{A}^{M}$ the inelastic mean free path for an electron $\mathrm{A}$ in the matrix $\mathrm{M}$.

Concerning the inelastic mean free path two methods were applied. The values of $\lambda_{S i 2 p}^{S i}$ and $\lambda_{S n 4 d}^{S n O_{2}}$ were estimated using the TPP2M method [31] which give respectively $30.8 \AA$ and $24.1 \AA$. As regards the value of $\lambda_{S i 2 p}^{S i}$, one may assumes that $\mathrm{d}_{\mathrm{Si}}<<\lambda_{S i 2 p}^{S i}$ which allows to modified the equation 1 and express the intensity of $\mathrm{Si} 2 \mathrm{p}$ as a function of the silicon atomic concentration per unit area in equation 3.

Eq. (3)

$$
I_{S i 2 p}=K T_{S i 2 p} \sigma_{S i 2 p} n_{s i} \times k_{S i 2 p}^{C_{3} N H_{8}}
$$

With $n_{S i}=N_{S i} d_{S i}$

The silicon surface concentration can be consequently expressed in function of the ratio of the intensities of Si $2 p$ and $\mathrm{Sn} 4 \mathrm{~d}$ following the equation 4 .

Eq. (4)

$$
n_{s i}=\frac{I_{S i 2 p}}{I_{S n 4 d}} \times \frac{T_{S n 4 d} \sigma_{S n 4 d} N_{S n} \lambda_{s n 4 d}^{S n O_{2}} \cos \theta}{T_{S i 2 p} \sigma_{S i 2 p}} \times \frac{k_{S n 4 d}^{A P T E S}}{k_{S i 2 p}^{C_{3} N H_{8}}}
$$

For $\lambda_{S i 2 p}^{C_{3} N H_{8}}$ and $\lambda_{S n 4 d}^{A P T E S}$, a method using quantitative structure-property relationships in organic materials [32] was used. Inelastic mean free paths were determined using the following expression:

Eq. (5)

$$
\lambda(\mathrm{nm})=\left[\frac{3.117\left({ }^{0} \chi^{V}\right)+0.4207 N_{\text {rings }}}{N_{\text {non-H }}}\right](\mathrm{E} / \mathrm{keV})^{0.79}
$$


With

$N_{\text {rings }}$ the number of aromatic six-member rings in the molecule,

$N_{n o n-H}$ the number of atoms in the molecule excluding hydrogen,

$E$ the kinetic energy of the electron travelling through the molecule and

${ }^{0} \chi^{V}=\sum_{\text {non-H atoms }}\left(\frac{1}{\sqrt{\delta^{(\mathrm{v})}}}\right)$ the zeroth-order valence connectivity index of the molecule and

$\delta^{(\mathrm{v})}$ the valence connectivity index which depends on the hybridization state and number of hydrogen atoms bonded to the atom considered. Values of $\delta^{(\mathrm{v})}$ were taken from literature using Bicerano work [33].

The values of inelastic mean free path and associated attenuation factors, assuming a collecting angle $\theta$ of $50^{\circ}$, are presented in the Table 1.

Table 1. Values of inelastic mean free path $\lambda$ and associated attenuation factor $\mathrm{k}$ calculated using the Cumpson method [32] for an electron with kinetic energy E travelling through a given matrix with thickness d.

\begin{tabular}{|c|c|c|c|c|}
\hline Matrix & $\begin{array}{c}\text { Peak, E Kinetic } \\
(\mathrm{eV})\end{array}$ & $\mathrm{d}^{\text {Matrix }}(\AA)$ & $\lambda_{\text {peak }}^{\text {Matrix }}(\mathrm{nm})$ & $\mathrm{k}_{\text {peak }}^{\text {Matrix }}$ \\
\hline APTES & Sn 4d, 1461 & 8 & 6.01 & 0.81 \\
\hline $\mathrm{C}_{3} \mathrm{NH}_{8}$ & Si $2 \mathrm{p}, 1384$ & $\sim 6$ & 4.83 & 0.82 \\
\hline
\end{tabular}

According to Table 1, the equation 4 can be simplified due to a ratio of the attenuation factors $k_{S n 4 d}^{A P T E S}$ and $k_{S i 2 p}^{C_{3} N_{8}}$ close to unity. Moreover, the kinetic energies of Si $2 \mathrm{p}$ and $\mathrm{Sn} 4 \mathrm{~d}$ are closed together and in range where the variation of the transmission function is weak. Following these assumptions, the silicon surface concentration $\mathrm{n}_{\mathrm{Si}}$ corresponding to the surface concentration of APTES molecules $\mathrm{n}_{\text {APTES }}$ can be described by: 
Eq. (6)

$$
n_{\text {APTES }}=n_{s i}=\frac{I_{S i 2 p}}{I_{S n 4 d}} \times \frac{\sigma_{S n 4 d} N_{S n} \lambda_{s n 4 d}^{S n O_{2}} \cos \theta}{\sigma_{S i 2 p}}
$$

It is worth noting that the main uncertainty on the estimation of APTES surface concentration comes from the electron collecting angle $\theta$ due to the roughness of the $\mathrm{SnO}_{2}$ substrates.

However, results of atomic force microscopy measurement, not presented here, have shown comparable roughness for the three substrates used which allows comparing the three processes of silanization in terms of surface concentrations of grafted APTES molecules.

Calculations were carried out with Scofield cross section of 0.817 for $\sigma_{S i 2 p}, 2.7$ for $\sigma_{S n \text { d }}$ and using an atomic concentration per unit volume of $\mathrm{Sn}$ in $\mathrm{SnO}_{2}$ of $2.77 \times 10^{22}$ atoms $/ \mathrm{cm}^{3}$. Table 2 reports the calculated covalently grafted APTES concentrations after the different synthesis ways of $\mathrm{SnO}_{2}$-APTES (anhydrous and hydrous liquid and vapor silanization). All the $\mathrm{SnO}_{2}$-APTES films were annealed after silanization at $110^{\circ} \mathrm{C}$, so no physisorbed APTES molecules present in the films.

Table 2. Calculated concentrations of APTES grafted on $\mathrm{SnO}_{2}$ obtained by different synthesis ways.

\begin{tabular}{|c|c|}
\hline & $n_{\text {APTES }}\left(\right.$ molecules $\left./ \mathrm{cm}^{2}\right)$ \\
\hline $\mathrm{SnO}_{2}$-APTES (vapor phase) & $4.7 \times 10^{14}$ \\
\hline $\mathrm{SnO}_{2}$-APTES (hydrous liquid) & $9 \times 10^{14}$ \\
\hline $\mathrm{SnO}_{2}$-APTES (anhydrous liquid) & $4.24 \times 10^{14}$ \\
\hline
\end{tabular}

The $\mathrm{SnO}_{2}$-APTES carried out by liquid silanization in presence of $5 \mathrm{vol} \% \mathrm{H}_{2} \mathrm{O}$ indicates the highest $n_{\text {APTES}}$. This means that more APTES is present on the $\mathrm{SnO}_{2}$ surface. The presence of $\mathrm{H}_{2} \mathrm{O}$ hydrolyzes ethoxy groups of the APTES to silanol groups which enhances the condensation reaction with hydroxyl groups of $\mathrm{SnO}_{2}$ and polymerization of APTES [17]. With vapor deposition and with liquid synthesis without water, the condensation is less favored due to the absence of water. In addition, vapor route and liquid silanization without water lead to almost the same concentration range $\left(n_{\mathrm{APTES}}=4.7 \times 10^{14}\right.$ and $n_{\mathrm{APTES}}=4.24 \times 10^{14}$, respectively). Therefore, 
hydrous solution may have promising role in the silanization process superior to vapor or anhydrous.

\subsection{Thermal stability of APTES}

To study the thermal stability of APTES, samples were in-situ annealed at $110^{\circ} \mathrm{C}$ (synthesis annealing temperature), $200{ }^{\circ} \mathrm{C}, 300{ }^{\circ} \mathrm{C}$ and $400{ }^{\circ} \mathrm{C}$ for $4 \mathrm{~h}$ at a pressure of $5.10^{-9} \mathrm{mbar}$. The evolution of the intensities of N 1s, C 1s, Si 2p, and Sn 3d are presented in Fig. 8. The decrease of the $\mathrm{N} 1 \mathrm{~s}$ peak intensity with temperature can be explained by the partial thermal degradation of amine group between $110^{\circ} \mathrm{C}$ and $400{ }^{\circ} \mathrm{C}$, while at $500{ }^{\circ} \mathrm{C}$ no more amine groups are present on the surface. The evolution of the intensity of $\mathrm{C} 1 \mathrm{~s}$ peak suggests also a decrease in the amount of carbon on the surface upon thermal treatment which is related to the degradation of different carbon bonds. After $4 \mathrm{~h}$ treatment at $500{ }^{\circ} \mathrm{C}$, a presence of carbon at the surface was still detected. This residual carbon was assigned to $\mathrm{Si}_{-} \mathrm{CH}_{2}$ bonds as the annealing treatments show no effects on the intensity of the Si 2p peak. The intensity of Sn 3d peak depends on the attenuating APTES overlayer. The increase of the intensity of Sn $3 d$ peak with temperature is consequently in accordance with the progressive degradation of the APTES film as the temperature increases. However, $\mathrm{Sn} 3 \mathrm{~d}$ is still less intense for $\mathrm{SnO}_{2}$-APTES heated at $500{ }^{\circ} \mathrm{C}$ than for pure $\mathrm{SnO}_{2}$. This could be related to the remaining silicon layer on the base $\mathrm{SnO}_{2}$ metal oxide surface. This study of APTES thermal stability on $\mathrm{SnO}_{2}$ showed that APTES grafted molecules started to degrade at $110{ }^{\circ} \mathrm{C}$; organic part was removed when heating while $\mathrm{Si}$ atoms stayed attached to $\mathrm{SnO}_{2}$. 

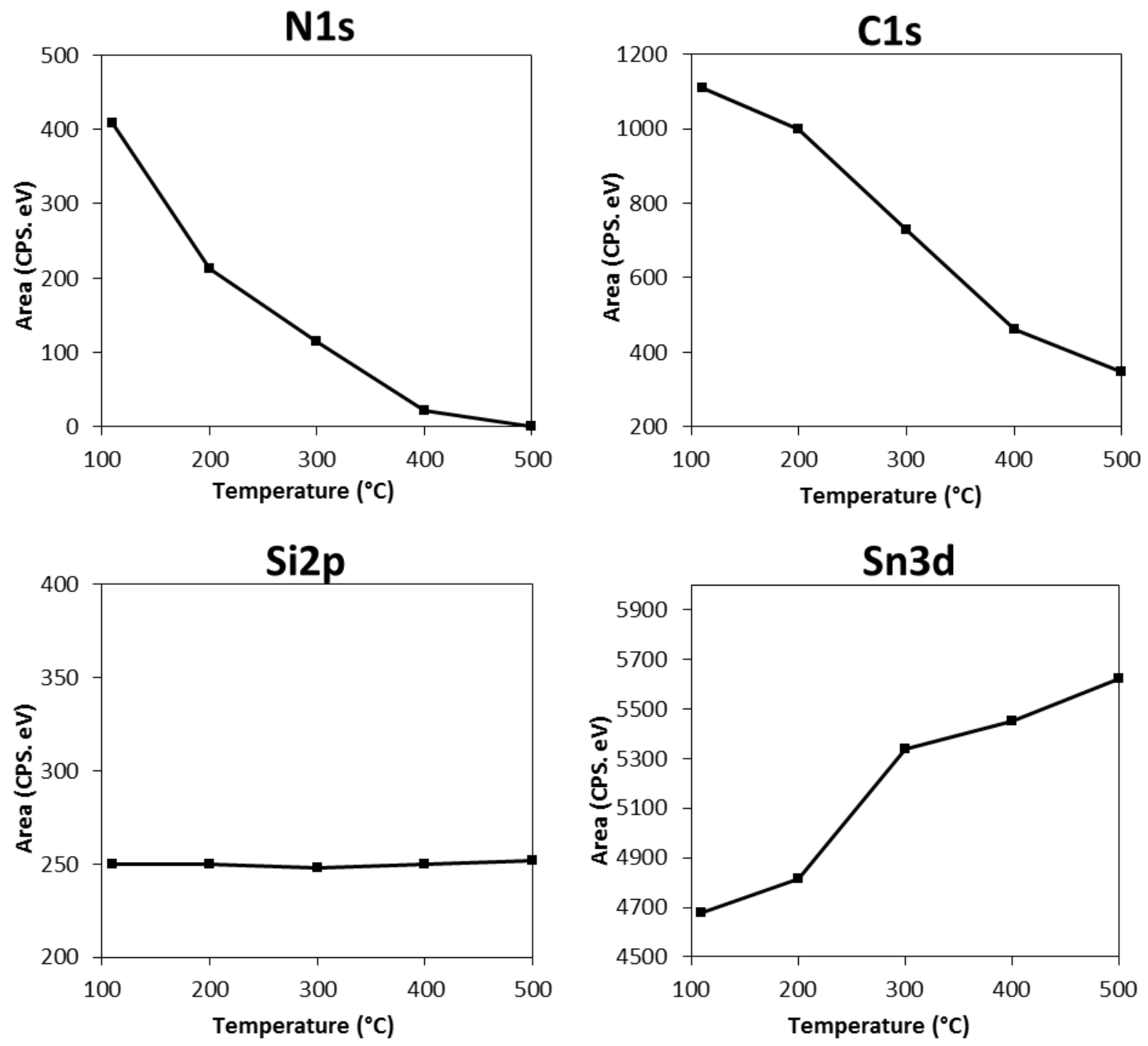

Fig. 8. Evolution of N 1s, C 1s, Si 2p and Sn 3d intensities in function of temperature for $4 \mathrm{~h}$ annealing treatment of $\mathrm{SnO}_{2}$-APTES synthetized in vapor phase.

\section{Conclusion}

APTES was deposited via vapor and liquid phases on $\mathrm{SnO}_{2}$ films to compare the synthesis effects. Liquid phase silanization with water clearly demonstrates more APTES grafting than vapor and liquid phase silanization without water. Water during the liquid phase silanization enhances the polymerization of APTES on the surface. Interestingly, $4 \mathrm{~h}$ reaction and $50 \mathrm{mM}$ 
were found to be sufficient to saturate the $\mathrm{SnO}_{2}$ film by APTES molecules. Furthermore, thermal treatment of APTES film on $\mathrm{SnO}_{2}$-APTES shows that the APTES start to degrade at temperature above $110{ }^{\circ} \mathrm{C}$, while no notable change in the amount of silicon between $110^{\circ} \mathrm{C}$ and $500{ }^{\circ} \mathrm{C}$ is observed. Amine groups had totally disappeared after heating the film at $500{ }^{\circ} \mathrm{C}$. We have calculated the concentration of APTES by calculating the amount of Si on the surface. The number of $\mathrm{Si}$ atoms of $\mathrm{SnO}_{2}$-APTES synthesized by liquid without water and vapor silanization is respectively $4.24 \times 10^{14}$ atoms. $\mathrm{cm}^{-2}$ and $4.7 \times 10^{14}$ atoms. $\mathrm{cm}^{-2}$, while it is $9 \times 10^{14}$ atoms.cm ${ }^{-2}$ with

the addition of $5 \mathrm{vol} \% \mathrm{H}_{2} \mathrm{O}$. In addition, the concentration of grafted APTES determined by XPS analyses are in good agreement with the previous ATR-FTIR results which confirm that the liquid route in the presence of water leads to more APTES grafting onto $\mathrm{SnO}_{2}$ indicating an almost 50\% improvement. Future research is needed to apply these promising initial results to more concrete applications in gas and bio sensors or related domains.

\section{References}

1. Le M, Jimenez C, Chainet E, Stambouli V (2015) A Label-Free Impedimetric DNA Sensor Based on a Nanoporous $\mathrm{SnO}_{2}$ Film: Fabrication and Detection Performance. Sensors 15:10686-10704.

2. Stambouli V, Labeau M, Matko I, et al (2006) Development and functionalisation of Sb doped $\mathrm{SnO}_{2}$ thin films for DNA biochip applications. Sens Actuators B Chem 113:10251033.

3. Garg N, Mohanty A, Lazarus N, et al (2010) Robust gold nanoparticles stabilized by trithiol for application in chemiresistive sensors. Nanotechnology 21:405501.

4. Matsubara I, Hosono K, Murayama N, et al (2005) Organically hybridized $\mathrm{SnO}_{2}$ gas sensors. Sens Actuators B Chem 108:143-147.

5. Wang B, Haick H (2013) Effect of Functional Groups on the Sensing Properties of Silicon Nanowires toward Volatile Compounds. ACS Appl Mater Interfaces 5:2289-2299.

6. Cecchetto L, Denoyelle A, Delabouglise D, Petit J-P (2008) A silane pre-treatment for improving corrosion resistance performances of emeraldine base-coated aluminium samples in neutral environment. Appl Surf Sci 254:1736-1743.

7. Ruckenstein E, Li Z (2005) Surface modification and functionalization through the selfassembled monolayer and graft polymerization. Adv Colloid Interface Sci 113:43-63. 
8. Hoffmann MWG, Mayrhofer L, Casals O, et al (2014) A Highly Selective and Self-Powered Gas Sensor Via Organic Surface Functionalization of p-Si/n-ZnO Diodes. Adv Mater 26:8017-8022.

9. Klug J, Pérez LA, Coronado EA, Lacconi GI (2013) Chemical and Electrochemical Oxidation of Silicon Surfaces Functionalized with APTES: The Role of Surface Roughness in the AuNPs Anchoring Kinetics. J Phys Chem C 117:11317-11327.

10. Ben Haddada M, Blanchard J, Casale S, et al (2013) Optimizing the immobilization of gold nanoparticles on functionalized silicon surfaces: amine- vs thiol-terminated silane. Gold Bull 46:335-341.

11. Herzer N, Hoeppener S, Schubert US (2010) Fabrication of patterned silane based selfassembled monolayers by photolithography and surface reactions on silicon-oxide substrates. Chem Commun 46:5634.

12. Pujari SP, Scheres L, Marcelis ATM, Zuilhof H (2014) Covalent Surface Modification of Oxide Surfaces. Angew Chem Int Ed 53:6322-6356.

13. Zhang F, Sautter K, Larsen AM, et al (2010) Chemical Vapor Deposition of Three Aminosilanes on Silicon Dioxide: Surface Characterization, Stability, Effects of Silane Concentration, and Cyanine Dye Adsorption. Langmuir 26:14648-14654.

14. Puleo DA (1996) Retention of enzymatic activity immobilized on silanized Co-Cr-Mo and Ti-6Al-4V. John Wiley \& Sons, Inc 97:222-228.

15. Shehada N, Brönstrup G, Funka K, et al (2015) Ultrasensitive Silicon Nanowire for RealWorld Gas Sensing: Noninvasive Diagnosis of Cancer from Breath Volatolome. Nano Lett 15:1288-1295.

16. Fiorilli S, Rivolo P, Descrovi E, et al (2008) Vapor-phase self-assembled monolayers of aminosilane on plasma-activated silicon substrates. J Colloid Interface Sci 321:235-241.

17. Kim J, Seidler P, Wan LS, Fill C (2009) Formation, structure, and reactivity of aminoterminated organic films on silicon substrates. J Colloid Interface Sci 329:114-119.

18. Acres RG, Ellis AV, Alvino J, et al (2012) Molecular Structure of 3Aminopropyltriethoxysilane Layers Formed on Silanol-Terminated Silicon Surfaces. J Phys Chem C 116:6289-6297. 
19. Aissaoui N, Bergaoui L, Landoulsi J, et al (2012) Silane Layers on Silicon Surfaces: Mechanism of Interaction, Stability, and Influence on Protein Adsorption. Langmuir 28:656-665.

20. Gourari H, Lumbreras M, Van Landschoot R, Schoonman J (1998) Elaboration and characterization of $\mathrm{SnO}_{2}-\mathrm{Mn}_{2} \mathrm{O}_{3}$ thin layers prepared by electrostatic spray deposition. Sens Actuators B Chem 47:189-193.

21. Chen JS, Lou XWD (2013) $\mathrm{SnO}_{2}$-Based Nanomaterials: Synthesis and Application in Lithium-Ion Batteries. small 9:1877-1893.

22. Tournier G, Pijolat C (2005) Selective filter for $\mathrm{SnO}_{2}$-based gas sensor: application to hydrogen trace detection. Sens Actuators B Chem 106:553-562.

23. Chiang C-H, Ishida H, Koenig JL (1980) The structure of $\gamma$-aminopropyltriethoxysilane on glass surfaces. J Colloid Interface Sci 74:396-404.

24. Tan G, Zhang L, Ning C, et al (2011) Preparation and characterization of APTES films on modification titanium by SAMs. Thin Solid Films 519:4997-5001.

25. Wen K, Maoz R, Cohen H, et al (2008) Postassembly Chemical Modification of a Highly Ordered Organosilane Multilayer: New Insights into the Structure, Bonding, and Dynamics of Self-Assembling Silane Monolayers. ACS Nano 2:579-599.

26. Rozlosnik N, Gerstenberg MC, Larsen NB (2003) Effect of solvents and concentration on the formation of a self-assembled monolayer of octadecylsiloxane on silicon (001). Langmuir 19:1182-1188.

27. Pasternack RM, Rivillon Amy S, Chabal YJ (2008) Attachment of 3(Aminopropyl)triethoxysilane on Silicon Oxide Surfaces: Dependence on Solution Temperature. Langmuir 24:12963-12971.

28. Wang B, Cancilla JC, Torrecilla JS, Haick H (2014) Artificial Sensing Intelligence with Silicon Nanowires for Ultraselective Detection in the Gas Phase. Nano Lett 14:933-938.

29. Tougaard S (2003) QUASES: Software for Quantitative XPS/AES of Surface Nanostructures by Analysis of the Peak Shape and Background (version 5.0). QUASES-Tougaard Inc Odense Den. www.quases.com.

30. Tougaard S (1997) Universality Classes of Inelastic Electron Scattering Cross-sections. Surf Interface Anal 25:137-154. 
31. Tanuma S, Powell CJ, Penn DR (1993) Calculations of electron inelastic mean free paths (IMFPS). IV. Evaluation of calculated IMFPs and of the predictive IMFP formula TPP-2 for electron energies between 50 and 2000 eV. Surf Interface Anal 20:77-89.

32. Cumpson PJ (2001) Estimation of inelastic mean free paths for polymers and other organic materials: use of quantitative structure-property relationships. Surf Interface Anal 31:23-34.

33. Bicerano J "Prediction of polymer Properties", (2nd edn), Marcel Dekker: New York, 1996. 